\title{
Rational and Nonrational Desires in Meno and Protagoras
}

\section{Citation}

Jones, Russel E. 2012. Rational and nonrational desires in Meno and Protagoras. Analytic Philosophy 53(2): 224-233.

\section{Published Version}

doi:10.1111/j.2153-960X.2012.00556.x

\section{Permanent link}

http://nrs.harvard.edu/urn-3:HUL.InstRepos:10735564

\section{Terms of Use}

This article was downloaded from Harvard University's DASH repository, and is made available under the terms and conditions applicable to Open Access Policy Articles, as set forth at http:// nrs.harvard.edu/urn-3:HUL.InstRepos:dash.current.terms-of-use\#OAP

\section{Share Your Story}

The Harvard community has made this article openly available.

Please share how this access benefits you. Submit a story.

Accessibility 


\title{
Rational and Nonrational Desires in Meno and Protagoras
}

\author{
Russell E. Jones \\ Harvard University
}

\begin{abstract}
A standard account in Socratic scholarship has it that Plato's Socrates is an intellectualist about motivation, in that Socrates accepts that both one's actions and one's desires always follow one's concurrent beliefs about what is in one's overall best interest. Brickhouse and Smith offer an alternative intellectualist interpretation of Socrates, on which Socrates accepts the standard account's claim with respect to actions but rejects it with respect to desires. On this alternative view, there are nonrational desires that are not always responsive to belief and may even affect belief. As part of their alternative account, Brickhouse and Smith offer interpretations of two important passages: Meno 77b6-78c2 and Protagoras 352b1358d4. I argue that the standard account makes better sense of Meno 77b6-78c2, and that an argument Brickhouse and Smith make against the standard account using Protagoras 352b1-358d4 fails.
\end{abstract}

In Socratic Moral Psychology, Thomas Brickhouse and Nicholas Smith make Socrates ${ }^{1}$ out to be an intellectualist about motivation. To be an intellectualist about motivation is to think that one's actions always follow one's beliefs about what is in one's overall best interest at the time of action. In this respect, Brickhouse and Smith are adopting a position that is fairly standard in Socratic scholarship. But Brickhouse and Smith emphatically reject another part of the standard picture of Socrates, that Socrates holds that not only one's actions but also one's desires always follow one's beliefs about what is in one's overall best interest at any given time. Or on a bit more cautious version of the standard picture, Socrates holds that insofar as one has desires that do not follow one's beliefs about what is in one's overall best

${ }^{1}$ This is the Socrates of Plato's so-called Socratic dialogues: roughly, Apology, Charmides, Crito, Euthydemus, Euthyphro, Gorgias, Hippias Major, Hippias Minor, Ion, Laches, Lysis, Protagoras, and Republic I (see Brickhouse and Smith (2010) 18, 30-37). Brickhouse and Smith also freely appeal to the Meno, which they take to be of a piece with the Socratic dialogues at least with respect to moral psychology (see Brickhouse and Smith (2010) 8). There has been some controversy about whether interpreting the Socrates of this particular set of dialogues is a viable or fruitful project. Brickhouse and Smith devote chapter 1 of the book to arguing that the project is viable and still bearing fruit. 
interest at any given time, these are not desires that serve as causes of one's actions.

On this view, only rational desires, which are those that follow the agent's beliefs

about her best interest, explain the actions she performs. ${ }^{2}$ It is this part of the

standard view that Brickhouse and Smith reject. On their account, Socrates thinks

that sometimes one's desires fail to follow one's beliefs about what is in one's

overall best interest at any given time, and that this fact is an important

motivational feature. That is to say, Socrates makes room for nonrational desires as

an important component of motivation.

Brickhouse and Smith think that Socrates tracks the distinction between

rational and nonrational desires by using two different terms (and their cognates)

for desires: 'boulêsis' for rational desire and 'epithumia' for nonrational desire. An

important passage for them is Charmides $167 \mathrm{e} 1-5^{3}$ :

Socrates: And do you think there is any desire (epithumia) that is a desire for no pleasure but for itself and the other desires?

Critias: Certainly not.

Socrates: Nor indeed any wish (boulêsis), I think, that wishes for no good but only for itself and the other wishes. ${ }^{4}$

\footnotetext{
2 Two proponents of the standard view whose work serves as a foil for Brickhouse and Smith's account are Terry Penner and Naomi Reshotko. See, for example, Penner (1991), Penner (1992), and Reshotko (2006).

${ }^{3}$ Throughout, I use translations from Cooper (1997) unless otherwise noted.

${ }^{4}$ See p. 51, where Brickhouse and Smith mark this as an important passage. Unfortunately, they spend very little space analyzing it. In the absence of such analysis, one might have at least two concerns about their use of this passage. First, the context is not at all a context where Socrates means to give an account of epithumia and boulêsis. These are mere examples designed to cast doubt on the general idea that there could be something that belongs to a kind $\mathrm{K}$, that does not take as its objects the things that other members of $\mathrm{K}$ take as their objects, but rather takes itself and the other members of $\mathrm{K}$ as its objects. By the time we get to the example of opinions (doxai), Socrates does not even bother to specify the proper objects of opinions, saying only, "Or [have you observed] an opinion that is of itself and the other opinions but opines nothing that other opinions do?" (168a3-4) This might lead us to think that Socrates is quite unconcerned with specifying the proper objects of his example kinds, and that they are being used merely in the service of casting doubt on the possibility of Critias' definition of temperance as knowledge of itself and other knowledges full stop.

Second (and as Brickhouse and Smith note on p. 51), immediately following his examples of epithumia and boulêsis, Socrates uses the example of erôs: "And would you say that there is a love (erôs) of such a sort as to be a love of no fine thing (kalou) but of itself and the other loves?" (167e7-
} 
Since Socrates here assigns different objects (the pleasant and the good, respectively) to epithumia and boulêsis, Brickhouse and Smith take this passage to indicate that Socrates has two different conceptions of desire. On their account, nonrational desires, epithumiai, may remain active and influence action even when the agent has a concurrent all-things-considered belief that it is not in his overall best interest to pursue the object of the nonrational desire. The account is still intellectualist, however, for nonrational desires can influence action only indirectly. Action always follows one's all-things-considered beliefs about what is in one's best interest, and nonrational desires may influence action only by influencing belief. ${ }^{5}$ But enough about the general account. Aside from these passages, Brickhouse and Smith rely centrally on their interpretations of two passages that have sometimes been taken to support the standard interpretation, Meno 77b678c2 and Protagoras 352b1-358d4, and it is on these passages that I want to focus

8) If we are taking Socrates to be making important distinctions in this passage, it looks as if erôs stands as a third kind of desire, with a third kind of object, alongside epithumia and boulêsis. So we might well wonder how erôs factors into Socrates' moral psychology. Judging from the rest of the book, erôs is hardly worth mentioning in an account of Socratic moral psychology. The only reference in the index to either 'love' or 'erôs' is to p. 51. Perhaps erôs (and perhaps also fear, the next example in the Charmides) is a species of epithumia, and so does not warrant independent consideration. (Though Lysis 221b7-8, a passage Brickhouse and Smith cite in this context on p. 52, makes this reading difficult: "And is it possible to desire and love something passionately (epithumounta kai erônta) without feeling friendly towards it?" If the 'kai' here is epexegetic, as it appears, then to love and to desire is the same thing. Even if the ' $k a i$ ' is not epexegetic, it remains difficult to see how erôs could here be a species of epithumia. On this general question in the Lysis, see Penner and Rowe (2005) 325, n.65 and the passages they cite there.) At any rate, the lack of discussion of Charmides 167e is a frustrating omission.

${ }^{5}$ In support of their account, in chapter 2 Brickhouse and Smith call attention to various passages which Socrates seems to talk of excessively filling up desires (e.g. Gorgias 505a6-10), to endorse displaying courage in the face of desires (e.g. Laches 191e4-7), and to warn against acting badly because of anger, fear, shame, and other such passions (e.g. Apology 21b1-23e3, 29e3-30a3, 32b1-d4, 34b6-d1). They argue that rational desires alone cannot account for the role of desire in these texts. 
my attention. ${ }^{6}$ While many scholars take these passages to rule out the possibility of desiring what one takes to be bad, it is crucial to the Brickhouse and Smith interpretation that they be able to offer an alternative reading on which the Meno and Protagoras allow for nonrational desires for apparent bad things. Ideally, Brickhouse and Smith would be able to rule out interpretations that support the standard view. But it may be enough for them to show that their reading is allowed by the text, and then to claim that it is superior to standard interpretations not because of considerations about the immediate passages in question but because it allows their overall interpretation, which has great explanatory power and cohesion, to get off the ground. I will argue that the standard account makes better sense of Meno 77b6-78c2, and that an argument Brickhouse and Smith make against the standard account using Protagoras 352b1-358d4 fails. ${ }^{7}$ At best, then, the Meno supports the standard account over against Brickhouse and Smith's alternative intellectualist account, while the Protagoras fails to undermine the standard account. Given the importance of these passages for understanding Socrates' account of desire, this poses a significant challenge to Brickhouse and Smith's overall account.

Meno 77b6-78c2

\footnotetext{
${ }^{6}$ On the Meno, see, for example, the discussion in Scott (2005), 46-53 and 219-21. On the Protagoras, see, for example, the discussion in Reshotko (2006), ch. 4. I take it that my arguments below are in keeping with the general accounts of both Scott and Reshotko.

${ }^{7}$ I have mentioned these problems for Brickhouse and Smith in Jones (2011), and I welcome the opportunity to develop them here.
} 
Commentators sometimes read Meno 77b6-78c2 as evidence that Socrates thinks no one ever desires what she recognizes to be bad. Meno defines virtue as desiring (epithumounta) fine things [= good things] and being able to acquire them (77b4-5). ${ }^{8}$ Socrates appears to target the first conjunct, desiring fine things, because there is no one who fails to satisfy it, and so it cannot serve an explanatory function in the definition. Initially, Meno thinks some people do fail to satisfy the first conjunct, for he thinks that some people desire bad things. But by the end of the passage, Meno agrees that no one desires (boulesthai) bad things (78a8-b2). Meno and Socrates allow that someone might desire something bad having mistaken it for a good, but not that someone might desire something bad that he recognizes as bad. So, the passage seems to support the standard view that desire follows belief, and thus to be a difficulty for Brickhouse and Smith's account.

Brickhouse and Smith offer an alternative reading of the passage that would leave open the possibility of desiring what one takes to be bad. They note the shift from 'epithumein' (which they associate with nonrational desire) to 'boulesthai' (which they associate with rational desire) that occurs part way through the argument, and read the passage as follows. Rather than targeting the claim that some people desire bad things, Socrates is targeting the claim that some people have a rational desire for bad things. But, he is leaving open the possibility that some people have nonrational desires for bad things.

\footnotetext{
8 'Fine things (tôn kalôn)' is clearly meant to be equivalent to 'good things (tôn agathôn)', as evidenced by Meno's affirmative answer to Socrates' immediately following question: "Do you mean that the man who desires beautiful things desires good things?"
} 
There is a difficulty for the Brickhouse and Smith interpretation. While I would not claim that Socrates' interlocutors must fully understand every step in an elenchos conducted on them, it does seem reasonable to suppose that they must have some grasp of the crucial moves. But it is hard to read Meno as having some grasp of the crucial move, on Brickhouse and Smith's interpretation. Meno initially (77b4-5) defines virtue as desiring (epithumounta) fine things (tôn kalôn) and being able to acquire them (dunaton einai porizesthai). But at the end of the argument, Socrates restates Meno's definition as follows (78b3-4; my trans.): “Didn't you just now say that virtue is to desire (boulesthai) good things (t'agatha) and to be able to acquire them (dunasthai)?" Meno agrees that this is what he said. But in fact, none of the three elements - desire, fine things, or ability to acquire - is preserved precisely from the original definition. The last part is easy to explain on any view: 'dunasthai' at 78b4 is an elliptical way of saying the same thing as 'dunaton einai porizesthai' at 77b4-5. The middle part is easy to explain on any view: Meno agreed at 77b6-7 that the one who desires (epithumounta) fine things desires good things, and so the shift from fine things at $77 \mathrm{~b} 4$ to good things at $78 \mathrm{~b} 4$ is unproblematic. The difficulty is with the shift from 'epithumein' to 'boulesthai'. If we suppose that the two terms are being used equivalently, then there is likewise no difficulty here, and so Socrates and Meno's agreement that the formulation at 78b3-4 expresses the same thing as the formulation at 77b4-5 makes complete sense. But if we suppose, with Brickhouse and Smith, that a key move - if not the key move - in the intervening argument is to distinguish the two terms, then we have a difficulty about what licenses replacing the one ('epithumein') with the other ('boulesthai'). 
Brickhouse and Smith's response to this difficulty seems to be that Socrates is using the terms advisedly throughout, carefully choosing one or the other depending on whether he means to be talking about rational desire or nonrational desire, but that Meno never manages to make the distinction. They write (p. 68-9):

Thus when [Socrates] uses "epithumein" he may be asking whether anyone ever forms a nonrational desire for what he knows to be a bad thing, and when he employs "boulesthai" he may be asking whether anyone ever forms a rational desire to be miserable and unhappy. We do not have to suppose that Meno manages to understand the distinction Socrates introduces in this way.... According to this second way of construing the argument, precisely because Meno himself had not yet managed to make the distinction between rational and nonrational desires, and how the objects of desires are represented in those different kinds of desire, the outcome is that his attempted definition of virtue now seems to him to be wholly indefensible.

This makes sense of the argument, if Socrates is merely trying to shoot down Meno's definition, whatever it takes to do so. As he has said just before at 75d1-2, Socrates could here say: "I have given my answer [here: argument]; if it is wrong, it is your job to refute it". And Meno, precisely because he does not understand that Socrates is relying on a distinction between 'epithumein' and 'boulesthai', would be unable to do so. But I suggested earlier that while it seems too strong to insist that Socrates' interlocutors must fully understand every step in an elenchos conducted on them, it does seem reasonable to suppose that they must have some grasp of the crucial moves. This is confirmed by the context of the quote from $75 \mathrm{~d} 1-2$. The response, "I have given my argument; if it is wrong, it is your job to refute it," is an appropriate response in an eristic and agonistic context, or as Grube translates: "If my questioner was one of those clever and disputatious debaters, I would say to him: 'I have given my answer; if it is wrong it is your job to refute it."' But Socrates goes on to establish that this is precisely not the context of the present discussion. He says: 
Then, if they are friends, as you and I are, and want to discuss with each other, they must answer in a manner more gentle and more proper to discussion. By this I mean that the answers must not only be true, but in terms admittedly known to the questioner. I too will try to speak in these terms. (75d2-7)

For him then only two pages later to rely on a distinction which he never makes explicit, which Meno fails to recognize, and which causes Meno to fail to be able to maintain his definition, as Brickhouse and Smith would have us believe, seems unlikely. This difficulty pushes us back to the competing interpretation, that there is a single sense of desire at play throughout, but two different terms are used to express this single sense of desire.

There remains a difficulty with the single-desire reading, however, at 78a4-8:

Does anyone desire (bouletai) to be miserable and unhappy? It doesn't seem so to me, Socrates.

Then no one desires (bouletai) bad things, Meno, if no one desires (bouletai) to be such. For what is it to be miserable but to desire (epithumein) and to acquire (ktasthai) bad things? ${ }^{9}$

The problem here is plain to see. In nearly the same breath, Socrates concludes that no one desires (bouletai) bad things, and seems to allow for the possibility that someone might desire (epithumein) bad things. But that is nonsense if there is only one sense of desire at play. Score one for the Brickhouse and Smith interpretation. Now we might seem to have a stalemate - a textual problem for each side - and a

\footnotetext{
${ }^{9}$ Here I depart somewhat from Grube's translation, in part to highlight the problem with taking 'bouletai' and 'epithumein' to be synonymous. I also depart from Grube in supplying 'no one' as the subject of the third instance of 'bouletai' (borrowing as the subject the final word and subject of the previous clause, 'oudeis'), rather than 'he'. The former translation better fits the inferential structure of the passage: That no one desires to be miserable and unhappy has just been established, and it is what is needed at this point in the argument to get to the conclusion Meno accepts, that no one desires bad things. However, I would contend that my interpretation below makes good sense of Grube's translation, as well, even if Grube's translation does not make the structure of the argument quite as plain.
} 
stalemate may be enough for Brickhouse and Smith, since they will have neutralized one of the passages often taken to be evidence for the standard account.

I believe there is a way for the standard account, on which there is a single sense of desire, to resolve this difficulty. Notice the inferential structure of the passage. Meno has agreed that those who desire bad things, believing that bad things harm their possessor, know that they will be harmed by them (we should add: if they acquire the bad things); that those who are harmed are to that extent miserable and unhappy; and that no one desires to be miserable and unhappy. Socrates then says, "No one desires bad things, if no one desires to be such." This is supposed to follow from what has come before. But what exactly is it that is supposed to follow? Is it the conditional claim that if no one desires to be miserable and unhappy, then no one desires bad things? I think not. Rather, I suggest it is simply that no one desires bad things. ${ }^{10}$ The 'if no one desires to be such' reiterates the claim that has been established immediately prior, that no one desires to be miserable and unhappy, and calls attention to its inferential role. The 'for' clause that follows - "For what is it to be miserable but to desire and to acquire bad things?" - also provides inferential support. ${ }^{11}$ But I suggest that just like the 'if no one desires to be such', it does not add any new content, but merely reiterates the argument. Since to be miserable just is to be harmed to the extent one is miserable, and since harm comes from acquiring bad things, and since people recognize these very facts, no one desires what is bad.

\footnotetext{
10 So does Meno. His next line is: "You are probably right, Socrates, and no one desires (boulesthai) bad things." (78a8-b2; Grube trans., with modifications)

11 I take there to be an assertion underlying the question (subject to the qualification in the following paragraph): To be miserable is nothing but to desire and to acquire bad things.
} 
It still needs to be explained why Socrates says, "For what is it to be miserable but to desire and to acquire bad things?" rather than simply, "For what is it to be miserable but to acquire bad things?". He does it to remind Meno of the chain of reasoning that led to this point. Meno endorsed the claim that those who desire bad things, believing that bad things harm their possessor, know that they will be harmed by them if they acquire the bad things. And it was a short step from there to the conclusion that no one desires what is bad. The 'for what is it to be miserable but to desire and to acquire bad things?' simply reminds Meno what got them started down this path, just as the 'if no one desires to be such' reminds Meno of the immediately prior inference. It is as if Socrates had said, "For on the view you have been defending, what is it to be miserable but to desire and to acquire bad things?" Together with the conclusion that no one desires what is bad, these two claims - 'if he does not want to be such' and 'what is it to be miserable but to desire and to acquire bad things?' - recall in chiastic order the full chain of inferences, and Meno is forced to admit that his position was untenable: "You probably speak the truth, Socrates, and no one desires bad things." Since the 'epithumein' in 'what is it to be miserable but to desire and to acquire bad things?' does not add anything new, Meno and Socrates say no more about it and are both quick to move back to Meno's original definition. Again, since the 'epithumein' does not add anything new, there is no need for Socrates and Meno to worry over the terminological difference between the original definition and the way it is recalled.

So, where are we? Earlier I noted that we had an apparent stalemate between the Brickhouse and Smith interpretation and the single-desire 
interpretation: Each faces a textual difficulty. Then I suggested a possible way for the single-desire interpretation to break the stalemate. If this result holds up, it poses a serious problem for the Brickhouse and Smith view, for it is evidence that Socrates has only one sort of desire in mind, though he uses multiple terms to refer to desire.

\section{Protagoras 352b-358d}

The other passage I want to address is Protagoras 352b-358d, the famous passage concerning the power of appearance. Here I want to be less textually focused, and zero in instead on an example Brickhouse and Smith use to differentiate themselves from and bolster their case against standard intellectualist interpretations. I will argue that this example does not threaten the standard interpretation.

In the Protagoras, Socrates argues against the view of the many that knowledge can be "dragged about like a slave" by desire, anger, pleasure, pain, love, fear, etc. The standard account explains Socrates' position by noting that knowledge implies belief, and maintaining that Socrates thinks that belief, desire (at least those desires with motivational force), and action are always in harmony. Since desire follows belief and no one ever acts contrary to her beliefs, no one ever acts contrary to her knowledge about her best interest. Against this, Brickhouse and Smith argue that we must recognize the psychological agency of nonrational appetites to interpret the Protagoras properly. This psychological agency is what gives objects the power of appearance, the power of an object to appear better to an agent than it 
really is. Of this power, Socrates says, "The power of appearance often makes us wander all over the place in confusion, often changing our minds about the same things and regretting our actions and choices with respect to things large and small" (356d4-7). As Brickhouse and Smith interpret Socrates (p. 71):

Socrates believes that appetites and passions can be either strong or weak and that a strong appetite or passion is more likely to cause an unknowing agent to believe that the pleasure at which it aims is in fact a good. It is appetite or passion, then, that accounts for the object of the appetite or passion having the power of appearance - and the stronger the appetite, the more "convincing" this power will be.

One argument against the standard interpretation is that it is committed to treating nonrational desires such as hunger simply as objective information, like perceptions. The many think - to anticipate a specific example Brickhouse and Smith discuss - that if someone believes at $t_{1}$ that eating the chocolate tart in front of him is not in his overall best interest, but then eats the tart at $t_{2}$, then he was (at least in some cases) overcome by pleasure between $t_{1}$ and $t_{2}$. The standard interpretation is committed to redescribing the case as one where the tart-eater has gained a new piece of objective information between $t_{1}$ and $t_{2}$. ( $O n$ the assumption that there is no new objective information available about the tart, and that the agent does not have new information about what goodness consists in, in this case the information must be about his nonrational desires.) But this just misses the challenge of the many completely, because no one would think that it is a case of being overcome by pleasure if someone changes his mind on the basis of new information. Moreover, nothing here adequately explains how an object, in this case the tart, which does not change (not even in its spatial or temporal relations to the agent), acquires the power to appear better at $t_{2}$ than it did at $t_{1}$. 
Consider the detailed example Brickhouse and Smith give of the tart-eater (76-9). The protagonist, $\mathrm{P}$, has just finished a large and satisfying meal. There is a chocolate tart for dessert, and the host places a piece directly in front of P. P is thoroughly sated, though, and recalling his doctor's advice to avoid rich foods, he declines to eat the tart and tells his host he should follow his doctor's advice. As Brickhouse and Smith describe it, "P obviously does not at $\mathrm{t}_{1}$ judge the pleasure of eating [the tart] to be worth the subsequent evil he will suffer" (77). The host leaves the tart in front of $\mathrm{P}$ and, after a few minutes during which $\mathrm{P}$ has digested enough of the meal to no longer feel completely sated, at $t_{2}$ we find $P$ devouring every last crumb of the tart. Apparently, P now judges the pleasure of eating the tart to be worth the risk his doctor has warned him about.

Brickhouse and Smith consider what it is that gives the tart the power of appearance at $\mathrm{t}_{2}$ that it lacked at $\mathrm{t}_{1}$. They claim that the standard interpretation cannot account for this case, for we must appeal to a change in P's appetite, a change that the standard account allegedly cannot accommodate. Instead, they offer us the central theory of the book, one on which nonrational desires have a causal influence on our beliefs and, through our beliefs, on our actions. P is a glutton who has allowed his appetites free rein. Between $t_{1}$ and $t_{2}$, his appetite for rich sweets, which was temporarily sated by his meal, regains strength. This increasing appetite then confers on the tart the power of appearance, the power to look better than it is, and as a result of this newly conferred power, $\mathrm{P}$ 's belief about whether eating the tart is in his overall best interest changes. 
I do not think the standard interpretation is threatened by this case. Here is an explanation that is consistent with the standard account. Brickhouse and Smith are right to say that none of the following change: anything intrinsic to the tart, the apparent size of the tart, the availability of the tart, the risk to P's health from eating the tart, and P's information about the risk to P's health from eating the tart. It is indeed P's appetite that has changed: It is part of the description of the case that he has gone from feeling completely sated to something less than complete satiety. But this is an objective piece of information of a sort that can be accommodated by the standard interpretation. This information is not objective in the sense that it is available to any perceiver. It is information available only to P. But it is objective information in the sense that it would be available first-personally to anyone in circumstances like P's, including those who are temperate with respect to desserts. It is information that should affect our pleasure calculus. It is simply more pleasant to eat tarts when you are not stuffed than to eat them when you are stuffed. The discomforts of tart eating while stuffed are fairly immediate (unlike, say, the discomforts of high cholesterol resulting from tart-eating, which are fairly distant), and the pleasure of eating is greater when it is not only a pleasure of the tongue but also of the belly. The pleasure of eating derives not only from the taste, but also from the ability of the food to make you feel comfortably (rather than uncomfortably) full. So the standard interpretation can allow that there is a change in appetite, that this change constitutes new objective information, that on the basis of this new information P recalculates and changes his mind about whether eating 
the tart is in his overall best interest, and that this change of mind result in $\mathrm{P}$ eating the tart. ${ }^{12}$

The specific case, then, does not threaten the standard account. But this response to the specific case also casts doubt on the argument I sketched initially, which had it that the standard account lacks resources to explain adequately how an object which does not itself change nevertheless acquires the power to appear better at $t_{2}$ than it did at $t_{1}$. Strictly speaking, the tart does not acquire that power; it had the power to produce distorted beliefs all along, as a result of its pleasures being so much nearer to the agent than the pains of high cholesterol. As soon as the other variables in the calculus had the right values to do so, the agent calculated incorrectly because of a failure to correctly weigh nearby pleasures against far away pains - that he should eat the tart. Moreover, this is an account of a case that the many would be happy to call a case of being overcome by pleasure. Whether they will accept the standard account of what it is to be overcome by pleasure is another matter altogether. But I fail to see why defenders of the standard account should concede that they cannot adequately handle the case. To be sure, I have not done much to show that the standard account is the best account of the detailed text of the Protagoras. But I have shown that the standard view need not admit defeat in the face of this Protagoras-inspired example of the tart-eater. Coupled with my argument that the standard account of Socratic intellectualism can handle Meno 77b6-78c2 better than Brickhouse and Smith's alternative intellectualist account,

12 I give substantially the same analysis of this case in Jones (2011) 150. 
this goes at least some way toward showing that the standard account remains a viable interpretation of Socrates. ${ }^{13}$

\section{Works Cited}

Brickhouse, T. and N. Smith. 2010. Socratic Moral Psychology. Cambridge: Cambridge University Press.

Cooper, J. (ed.) 1997. Plato: Complete Works. Indianapolis: Hackett.

Jones, R. 2011. “Review of Brickhouse and Smith 2010.” Polis 28: 147-152.

Penner, T. 1991. "Desire and Power in Socrates: The argument of Gorgias 466A$468 \mathrm{E}$ that orators and tyrants have no power in the city." Apeiron 24: 147202.

. 1992. "Socrates and the Early Dialogues." In R. Kraut (ed.). The Cambridge Companion to Plato. Cambridge: Cambridge University Press, pp. 121-169.

Penner, T. and C. Rowe. 2005. Plato's Lysis. Cambridge: Cambridge University Press.

Reshotko, N. 2006. Socratic Virtue: Making the Best of the Neither-Good-Nor-Bad. Cambridge: Cambridge University Press.

Scott, D. 2005. Plato’s Meno. Cambridge: Cambridge University Press.

${ }^{13}$ I thank Tom Brickhouse and Nick Smith, as well as Travis Butler, Dan Devereux, Keith McPartland, Mark McPherran, Bryan Reece, the audience at the 2011 Arizona Colloquium in Ancient Philosophy, and the audience at an author-meets-critics session at the 2011 Pacific APA meeting for helpful comments and discussion. 